\title{
Analisa QoS Pada Jaringan MPLS Ipv6 Berbasis Routing OSPF
}

\author{
Imas Dwi Rahmawati ${ }^{1}$,Akuwan Saleh ${ }^{2}$, Idris Winarno ${ }^{2}$ \\ ${ }^{1}$ Mahasiswa Politeknik Elektronika Negeri Surabaya, Jurusan Teknik Telekomunikasi \\ ${ }^{2}$ Politeknik Elektronika Negeri Surabaya Institut Teknologi Sepuluh Nopember \\ Kampus ITS, Surabaya 60111 \\ e-mail :im45_cut3@yahoo.com e-mail : akuwan@eepis-its.edu, idris@eepis-its.edu
}

\begin{abstract}
Abstrak
Multi Protocol Label Switching (MPLS), merupakan arsitektur jaringan yang didefinisikan oleh IETF untuk memadukan mekanisme label swapping di layer dua dengan routing di layer tiga yang berguna untuk mempercepat pengiriman paket Routing eksplisit memberikan semua keuntungan MPLS, termasuk kemampuan melakukan traffic engineering dan routing kebijakan.

Kecepatan transfer data menjadi masalah yang sering dialami dalam jaringan komputer, sehingga diperlukan proses yang cepat untuk mengatasi pengiriman dan pengambilan data tersebut dengan mengutamakan efisiensi waktu, sehingga user tidak perlu membuang banyak waktu. Dengan demikian, dibuatlah sebuah jaringan komputer dengan memanfaatkan teknologi berbasis Multiprotocol Label Switching (MPLS). Jaringan MPLS ini merupakan jaringan yang akan menambahkan label pada setiap paket yang akan dikirimkan, dengan pelabelan ini maka data yang akan dikirimkan akan menjadi lebih cepat sampai pada tujuan. Hal ini dikarenakan router hanya akan menganalisa label yang diberikan pada tiap paket.

Pada tugas akhir ini akan menitikberatkan pada pembangunan aplikasi jaringan secara test-bed yang mampu merepresentasikan MPLS pada jaringan IPv6 berbasis OSPF beserta analisis terhadap parameter QoS dari hasil pengukuran. Pada tugas akhir ini menitikberatkan pada pembangunan aplikasi jaringan secara test-bed yang mampu merepresentasikan MPLS pada jaringan IPv6 beserta analisis terhadap parameter QoS. Dari hasil pengukuran didapatkan bahwa jaringan MPLS (Multi Protocol Label Switching) akan bekerja
\end{abstract}

secara optimal apabila terdapat banyak switching dalam sebuah jaringan, selain itu jaringan MPLS akan terasa dampaknya jika pengiriman data dilakukan dalam kapasitas ber-gigabyte.

Kata Kunci: MPLS, IPv6, QoS

\section{Pendahuluan}

Riset dan inovasi dalam teknologi telekomunikasi dikembangkan atas dorongan kebutuhan mewujudkan jaringan informasi yang menyediakan layanan yang beraneka ragam, memiliki kapasitas tinggi sesuai kebutuhan yang berkembang mudah diakses dari mana dan kapan saja serta terjangkau harganya. Network yang memenuhi kebutuhan itu adalah broadband network yang menghantarkan data paket secara efisien, scalable, memungkinkan diferensiasi dalam satu sistem, serta mampu diakses secara mobile.

Internet yang dengan protokol IP saat ini telah berkembang lebih cepat sehingga IP sangat baik dari segi skalabilitas, yang membuat teknologi Internet menjadi cukup murah. Dalam proyek akhir ini diperlukan penggunaan IPv6 yang disebut sebagai IP next generation, bagi penyelenggara telekomunikasi merupakan teknologi yang perlu diantisipasi pertumbuhan demand dan implementasinya.

Pada saat ini hampir semua aplikasi bisnis khususnya di segmen korporasi masih memanfaatkan teknologi IP eksisting yakni IPv4, namun demikian seiring berkembangnya zaman akan mengakibatkan IP pada versi4 dapat mengalami overload (Kelebihan user) sehingga diperlukan solusi yang terdapat di dalam desain IPv6 yang merupakan pemicu percepatan implementasi.Adapun 
kelebihan-kelebihan yang ditawarkan IPv6 adalah sebagai berikut: IPv6 merupakan solusi bagi keterbatasan alamat IPv4 (32 bit). IPv6 dengan 128 bit memungkinkan pengalamatan yang lebih banyak, yang memungkinkan IP-nisasi berbagai perangkat (PDA, handphone, perangkat rumah tangga, perlengkapan otomotif). Seperti dijelaskan di atas bahwa dalam segi skalabilitas IP sangat baik digunakan,sehingga IP membuat teknologi Internet menjadi cukup murah. Namun IP memiliki kelemahan serius pada implementasi QoS. Karena hal inilah maka dikembangkan beberapa metode untuk memperbaiki kinerja jaringan IP, antara lain dengan MPLS yang bersifat alami bagi dunia IP. Seperti kita ketahui bersama bahwa MPLS adalah suatu teknologi penyampaian paket pada jaringan backbone (jaringan utama) berkecepatan tinggi yang menggabungkan beberapa kelebihan dari sistem komunikasi circuitswitched dan packet switched yang melahirkan teknologi yang lebih baik dari keduanya. MPLS bekerja pada packets dengan MPLS header, yang berisi satu atau lebih label. Header MPLS terdiri atas 32 bit data, termasuk 20 bit label, 2 bit eksperimen, dan 1 bit identifikasi stack, serta 8 bit TTL. Label pada MPLS digunakan untuk proses forwarding, termasuk proses traffic engineering.

\section{Teori Penunjang}

\section{Multi Protokol Label Switching}

Multi-Protokol Label Switching
(MPLS) ,adalah arsitektur jaringan
(network) yang didefinisikan oleh IETF
untuk memadukan mekanisme label
swapping di layer dua dengan routing di
layer tiga untuk mempercepat pengiriman
paket. Arsitektur MPLS dirancang guna
memenuhi karakteristik-karakteristik wajib
dari sebuah jaringan kelas carrier
(pembawa) berskala besar.
MPLS dikatakan sebagai multiprotocol
karena teknik ini mampu digunakan untuk
lebih dari sekedar network layer protocol.
Menurut kerangka dokumen Internet
Engineering Task Force (IETF) MPLS
sebagai teknologi dasar label swaping,
yang diharapkan dapat menjadi solusi

peningkatan network layer routing untuk meningkatkan performansi jaringan. IETF membentuk kelompok kerja MPLS pada tahun 1997 guna mengembangkan metode umum yang distandarkan. Tujuan dari kelompok kerja MPLS ini adalah untuk menstandarkan protokol-protokol yang menggunakan teknik pengiriman label swapping (pertukaran label).

\section{Internet Protokol versi 6(IPv6)}

IPv4 yang merupakan pondasi dari Internet telah hampir mendekati batas akhir dari kemampuannya, dan IPv6 yang merupakan protokol baru telah dirancang untuk dapat menggantikan fungsi IPv4. Motivasi utama untuk mengganti IPv4 adalah karena keterbatasan dari panjang addressnya yang hanya 32 bit saja serta tidak mampu mendukung kebutuhan akan komunikasi yang aman, routing yang fleksibel maupun pengaturan lalu lintas data.

IP versi 6 (IPv6) adalah protokol Internet versi baru yang didesain sebagai pengganti dari Internet protocol versi 4 (IPv4) yang didefinisikan dalam RFC 791. IPv6 yang memiliki kapasitas address raksasa (128 bit), mendukung penyusunan address secara terstruktur, yang memungkinkan Internet terus berkembang dan menyediakan kemampuan routing baru yang tidak terdapat pada IPv4. IPv6 memiliki tipe address anycast yang dapat digunakanuntuk pemilihan route secara efisien. Selain itu IPv6 juga dilengkapi oleh mekanisme penggunaan address secara local yang memungkinkan terwujudnya instalasi secara Plug\&Play, serta menyediakan platform bagi cara baru pemakaian Internet, seperti dukungan terhadap aliran data secara real-time, pemilihan provider, mobilitas host, end-toend security, ataupun konfigurasi otomatis.

\section{Representasi Alamat pada IPv6}

Model $x: x: x: x: x: x: x: x$ dimana ' $x$ ' berupa nilai hexadesimal dari 16 bit porsi alamat, karena ada 8 buah ' $\mathrm{x}$ ' maka jumlah totalnya ada $16 * 8=128$ bit. Contohnya adalah: 
FEDC:BA98:7654:3210:FEDC:BA98:76 54:3210

Jika format pengalamatan IPv6 mengandung kumpulan group 16 bit alamat, yaitu ' $\mathbf{x}$ ', yang bernilai 0 maka dapat direpresentasikan sebagai '::'. Contohnya adalah :

\section{FEDC:0:0:0:0:0:7654:3210}

Menghasilkan bentuk alamat:

FEDC::7654:3210

Model x:x:x:x:x:x:d.d.d.d dimana 'd.d.d.d' adalah alamat IPv4 semacam 167.205.25.6 yang digunakan untuk automatic tunnelling. Contohnya adalah :

0:0:0:0:0:0:167.205.25.6

atau

$:: 167.205 .25 .6$

0:0:0:0:0:ffff:167.205.25.7 atau :ffff:167.205.25.7

Jadi jika sekarang anda mengakses alamat di internet misalnya 167.205.25.6 pada saatnya nanti format tersebut akan digantikan menjadi semacam ::ba67:080:18. Sebagaimana IPv4, IPv6 menggunakan bit mask untuk keperluan subnetting yang direpresentasikan sama seperti representasi prefix-length pada teknik CIDR yang digunakan pada IPv4, misalnya :

\section{3ffe:10:0:0:0:fe56:0:0/60}

menunjukkan bahwa 60 bit awal merupakan bagian network bit. Jika pada IPv4 anda mengenal pembagian kelas IP menjadi kelas A, B, dan C maka pada IPv6 pun dilakukan pembagian kelas berdasarkan fomat prefix (FP) yaitu format bit awal alamat. Misalnya :

\section{3ffe:10:0:0:0:fe56:0:0/60}

maka jika diperhatikan 4 bit awal yaitu hexa ' 3 ' didapatkan format prefixnya untuk 4 bit awal adalah 0011 (yaitu nilai ' 3 ' hexa dalam biner).

\section{Kelas Ipv6}

Ada beberapa kelas IPv6 yang penting yaitu:

a) Aggregatable Global Unicast Addresses : termasuk di dalamnya adalah alamat IPv6 dengan bit awal 001.

b) Link-Local Unicast Addresses : termasuk di dalamnya adalah alamat IPv6 dengan bit awal 1111111010.

c) Site-Local Unicast Addresses : termasuk di dalamnya adalah alamat IPv6 dengan bit awal 1111111011.

d) Multicast Addresses : termasuk di dalamnya adalah alamat IPv6 dengan bit awal 11111111.

\section{Routing}

Routing merupakan fungsi yang bertanggung jawab membawa data melewati sekumpulan jaringan dengan cara memilih jalur terbaik untuk dilewati data. Tugas Routing akan dilakukan device jaringan yang disebut sebagai Router. Router merupakan komputer jaringan yang bertugas atau difungsikan menghubungkan dua jaringan atau lebih.

\section{- Dynamic Routing}

Dynamic routing adalah salah satu tipe routing, dimana terjadi proses pembelajaran oleh router dan mengupdate table routing jika terjadi perubahan.

\section{$\checkmark$ OSPF v3(Open Shortest Path First versi 3)}

Open Shortest Path First adalah routing protokol yang digunakan pada IPv6. OSPF ini berdasarkan atas Link-state dan bukan berdasarkan atas jarak. Setiap node dari OSPF mengumpulkan data state dan mengumpulkan pada Link State Packet. LSP dibroadcast pada setiap node untuk mencapai keseluruhan network. Setelah seluruh network memiliki "map" hasil dari informasi LSP dan dijadikan dasar link-state dari OSPF. Kemudian setiap OSPF akan melakukan pencarian dengan metode SPF (Shortest Path First) untuk menemukan jarak yang lebih 
efisien. Routing table yang dihasilkan berdasarkan atas informasi LSP yang didapat sehingga OSPF memberikan informasi LSP secara flood, karena OSPF sudah memiliki kemampuan untuk memilih informasi LSP yang sama maka flood ini tidak mengakibat exhousted. OSPF ini menggunakan protokol TCP bukan UDP, mendukung VLSM (Variable Length Subnet Mask).OSPF menggunakan algoritma Shortest Path First (SPF) oleh Dijkstra

\section{QoS Support}

QoS adalah kemampuan dalam menjamin pengiriman arus data penting atau dengan kata lain kumpulan dari berbagai kriteria performansi yang menentukan tingkat kepuasan penggunaan suatu layanan. Networking Manager membutuhkan QoS, karena berbagai hal diantaranya adalah :

a. Dapat menjamin jumlah bandwidth yang pasti untuk beberapa aplikasi.

b. Dapat mengontrol latency.

c. Dapat menyediakan SLA yang dapat dikuantifikasi.

d. Dapat membuat beberapa level QoS untuk banyak langganan.

Sekarang kita bahas istilah - istilah dalam Quality of Service :

\section{$\checkmark$ Bandwidth}

Bandwidth adalah kapasitas atau daya tampung kabel ethernet agar dapat dilewati trafik paket data dalam jumlah tertentu. Bandwidth juga bisa berarti jumlah konsumsi paket data per satuan waktu dinyatakan dengan satuan bit per second [bps]. Bandwidth internet di sediakan oleh provider internet dengan jumlah tertentu tergantung sewa pelanggan. Dengan QoS kita dapat mengatur agar user tidak menghabiskan bandwidth yang di sediakan oleh provider.

\section{$\checkmark$ Latency}

Jika kita mengirimkan data sebesar 3 Mbyte pada saat jaringan sepi waktunya 5 menit tetapi pada saat ramai 15 menit, hal ini di sebut latency. Latency pada saat jaringan sibuk berkisar 50 - 70 msec.

\section{$\checkmark$ Losses}

Losses adalah jumlah paket yang hilang saat pengiriman paket data ke tujuan, kualitas terbaik dari jaringan LAN / WAN memiliki jumlah losses paling kecil.

$\checkmark$ Availability

Availability berarti ketersediaan suatu layanan web, smtp, pop3 dan aplikasi pada saat jaringan LAN / WAN sibuk maupun tidak.

\section{Perancangan Sitem}

Dari gambar rancangan sistem dibawah, diperlukan 1 buah server, 1 buah client, 3 buah LSR ( 2 buah LSR sebagai ingress dan egress, 1 buah LSR intermediate). Server mengirimkan sebuah data yang dapat berupa suara, file, maupun gambar. Trafik dari server menuju client 1 melalui mapping LSP 2 / LSP1. Untuk dapat mengirimkan sebuah data dari server menuju ke client, maka akan melewati jalur LSR 1 ingress yang berfungsi untuk mengatur trafik saat paket memasuki jaringan MPLS. Sedangkan LSR 3 egress berfungsi untuk mengatur trafik saat paket meninggalkan jaringan MPLS menuju ke LER. LER adalah router yang menghubungkan jaringan MPLS dengan jaringan lainnya seperti frame relay, ATM dan ethernet.

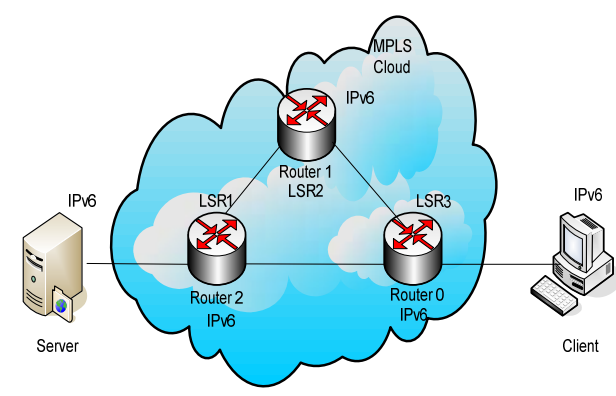

Gambar 1 Diagram jaringan MPLS

Dalam perencanaan ini diperlukan software pendukung yaitu sebagai berikut:

1. System operasi Linux Fedora Core 5. Sistem operasi yang digunakan pada PC Router serta adalah Linux Fedora Core 5 2.6.15-1.

2. System operasi Linux Debian. 
Sistem operasi yang digunakan pada komputer server adalah Linux Debian Lenny Kernel 2.6.26-2-686.

3. Paket MPLS yang akan digunakan adalah

a. linux-2.6.20.tar.bz2

b. mpls-linux-1.956.tar.bz2

c. ebtables-2.0.8-

0_mpls_1.956.i386.rpm

d. iproute-2.6.16-

1_mpls_1.956.i386.rpm

e. iptables-1.3.5-1_mpls_1.956.i386.rpm

4. $\quad$ Ping

5. Wireshark

Wireshark merupakan software yang digunakan untuk melakukan analisa jaringan komputer, wireshark dapat digunakan untuk menganalisa beberapa parameter QoS seperti jitter, delay,

throughput, dan packet loss. Serta dapat mengcapture protokol yang sedang berjalan dalam jaringan tersebut.

6. Iperf

Iperf adalah software berbasis console yang digunakan untuk membangkitkan traffic UDP dan TCP, Iperf berjalan pada model client - server, server Iperf membangkitkan traffic UDP atau TCP pada sisi client.

7. Iptraf

Dibawah ini merupakan tabel pengalamatan IPv6 yang digunakan pada sistem di atas:

\begin{tabular}{|l|l|l|}
\hline No & \multicolumn{1}{|c|}{$\begin{array}{c}\text { Nama } \\
\text { komputer }\end{array}$} & \multicolumn{1}{c|}{ Ipv6 } \\
\hline 1 & Server & Eth1: \\
& & 2001:660:5503:276a::3/64 \\
\hline 2 & Router1(LER1) & Eth0: \\
& & 2001:660:5503:276a::4/64 \\
& & $2001: 660: 5503: 276 b:: 3 / 64$ \\
& & Eth2: \\
& & $2001: 660: 5503: 276 \mathrm{c}:: 3 / 64$ \\
\hline 3 & Router2(LSR) & Eth1: \\
& & $2001: 660: 5503: 276 \mathrm{c}:: 4 / 64$ \\
& & Eth2: \\
& & $2001: 660: 5503: 276 \mathrm{~d}:: 3 / 64$ \\
\hline 4 & Router3(LER2) & Eth0: \\
& & $2001: 660: 5503: 276 \mathrm{e}:: 4 / 64$ \\
& & Eth1: \\
& & $2001: 660: 5503: 276 \mathrm{~b}:: 4 / 64$ \\
& & Eth2: \\
\hline 5 & Client & Eth0: \\
& & $2001: 660: 5503: 276 \mathrm{~d}:: 4 / 64$ \\
\hline
\end{tabular}

\section{Pengujian Dan Analisa}

\section{A Delay}

Berdasarkan data pada pengukuran testbed secara keseluruhan dapat dijelaskan bahwa perbandingan antara jaringan OSPF dan jaringan MPLS adalah sebagai berikut. Untuk data delay TCP secara pengukuran testbed dengan menggunakan jaringan OSPF terlihat pada table di bawah ini:

Tabel 4-15 Nilai pengukuran delay pada paket

\begin{tabular}{|r|c|c|c|}
\multicolumn{2}{|c|}{} & \multicolumn{2}{|c|}{ Delay } \\
\cline { 3 - 4 } No & \multirow{2}{*}{ Data } & $\begin{array}{c}\text { OSPF } \\
\text { IPV6 }\end{array}$ & $\begin{array}{c}\text { MPLS } \\
\text { IPV6 }\end{array}$ \\
\cline { 3 - 4 } & & (ms) & (ms) \\
\hline 1 & Test1.doc & 0.682 & 1.544 \\
\hline 2 & Test2.exe & 0.712 & 1.24 \\
\hline 3 & Test3.exe & 0.191 & 1.249 \\
\hline 4 & Test4.exe & 0.148 & 1.162 \\
\hline 5 & Test5.exe & 0.167 & 1.207 \\
\hline \multicolumn{2}{|c|}{ TOTAL } & $\mathbf{0 . 3 8 0}$ & $\mathbf{1 . 2 8 0}$ \\
\hline
\end{tabular}

Dari table tersebut diperoleh nilai rata rata delay pada jaringan OSPF sebesar 0.380 ms, dan nilai delay pada jaringan MPLS sebesar 1.280 ms. Data tabel dapat ditampilkan dalam bentuk grafik sehingga menghasilkan bentuk seperti di bawah ini:

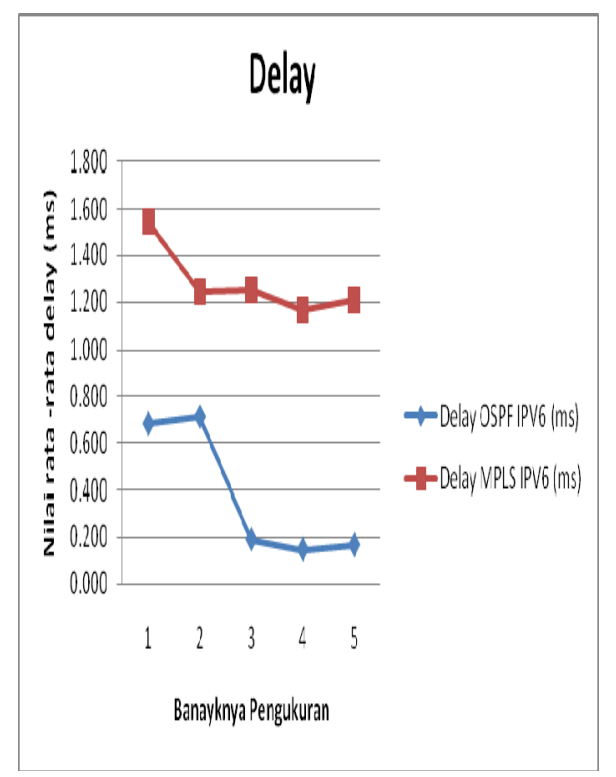

Gambar 4.27. Grafik delay pengukuran tcp keseluruhan 
Dari hasil tersebut dapat dikatakan bahwa delay pada jaringan OSPF mengalami stabilan, begitupun juga dengan delay pada MPLS. Sehingga dapat dikatakan ketika proses pengiriman data terjadi (dengan mengaktifkan socket pada server dan client), data dialirkan melalui router. Pada jaringan OSPF terdapat jedah untuk peng-update-an database, pengupdate-an ini terjadi untuk memperbaharui dabase yang terdapat pada router, yang berguna sebagai pengidentifikasian neighbor serta mpengidentifikasian nilai cost(jalur mana yang memiliki jalur terpendek, sehingga data yang dikirimkan akan cepat sampai)

Untuk jaringan MPLS, delay yang dihasilkan sangat stabil(berkisar antara 1,1ms $-1.7 \mathrm{~ms}$ ), delay tersebut digunakan oleh router untuk pemrosesan data. Dimana router yang paling aktif adalah router LER1 dan router LER2, hal ini dikarenakan pada LER1 memerlukan waktu untuk mengganti menambahkan label pada paket data sehingga memerlukan waktu, jangka waktu yang diperlukan pun cukup stabil antara 0.9ms 1ms, sedangkan untuk LER2 memerlukan waktu untuk melepaskan pelabelan tersebut dan mengarahkan paket data sesuai dengan tujuannya, sehingga wktu yang diperlukan oleh LER2 sekita $0,9 \mathrm{~ms}-1 \mathrm{~ms}$.

\section{B. Throughput}

Berdasarkan data pada pengukuran testbed secara keseluruhan dapat dijelaskan bahwa perbandingan antara jaringan OSPF dan jaringan MPLS adalah sebagai berikut. Untuk data throughput TCP secara pengukuran testbed dengan menggunakan jaringan OSPF terlihat pada table di bawah ini:

Tabel 4-16 Nilai pengukuran throughput pada paket TCP

\begin{tabular}{|r|l|r|r|}
\hline \multirow{2}{*}{ No } & \multirow{2}{*}{ Data } & \multicolumn{2}{|c|}{ Throughput } \\
\cline { 3 - 4 } & & OSPF IPV6 & \multicolumn{1}{c|}{ MPLS IPV6 } \\
\cline { 3 - 4 } & & (Mbits/sec) & (Mbits/sec) \\
\hline 1 & Test1.doc & 0.736 & 4.190 \\
\hline 2 & Test2.exe & 1.888 & 4.958 \\
\hline 3 & Test3.exe & 5.096 & 4.517 \\
\hline 4 & Test4.exe & 28.31 & 4.755 \\
\hline 5 & Test5.exe & 42.000 & 3.891 \\
\hline 6 & Test6.exe & 47.990 & 18.254 \\
\hline 7 & Test7.iso & 59.182 & 43.591 \\
\hline \multicolumn{2}{|c}{} & & 12.022 \\
\hline
\end{tabular}

Dari hasil tersebut dapat dikatakan bahwa throughput rata - rata yang dihasilkan oleh jaringan OSPF sebesar 26.457 MBit/sec sedangkan untuk jaringan MPLS sebesar 12.022 MBit/sec. Data tabel dapat ditampilkan dalam bentuk grafik sehingga menghasilkan bentuk seperti di bawah ini:

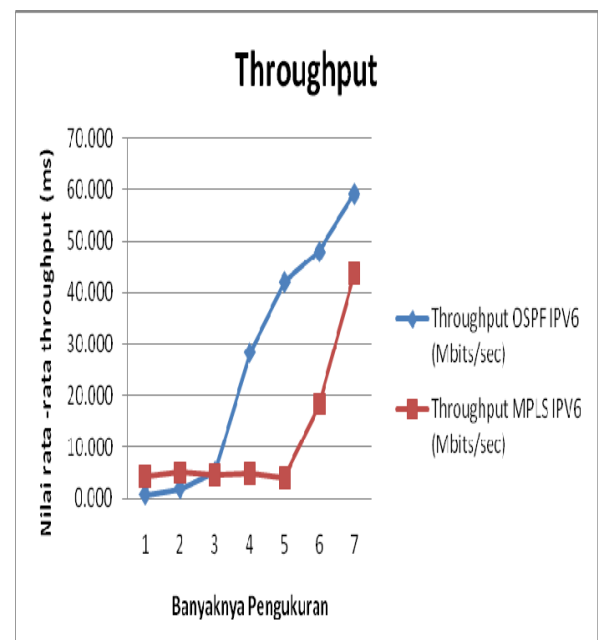

Gambar 4.28. Grafik throughput pengukuran tcp keseluruhan

Dari hasil grafik tersebut dapat dilihat bahwa throughput MPLS mengalami kenaikan secara bertahap, dari 3MBit/sec menjadi 43.591, sedangkan untuk jaringan OSPF mengalami kenaikan secara perlahan juga dari $1.888 \mathrm{MBits} / \mathrm{sec}$ menjadi 59.182 MBits/sec.

\section{Kesimpulan}

Setelah dilakukan pengujian dan analisa pada aplikasi data yang diimplementasikan pada jaringan MPLS, maka dapat disimpulkan sebagai berikut:

1. Jaringan OSPF IPV6 memiliki system kerja berdasarkan cost, sehingga diperlukan update database utnuk melakukan pemilihan route yang terpendek.

2. Delay yang terjadi pada jaringan MPLS lebih besar dari pada delay OSPF.Hal ini dikarenakan pada jaringan MPLS terdapat 2 LER dimana pada router LER ini diperlukan beberapa pemrosesan, Karena pada router inilah pelabelaan dimulai(untuk LER1) dan dilepaskan (Untuk LER2). 


\section{Daftar Pustaka}

[1]Bachtiar.Dodi, "Analisa Performansi Trafik Pada Jaringan MPLS", EEPIS-ITS,Surabaya : 2009

[2]Watsuwibowo, Kuncoro (2003), "Kuliah Umum Ilmu Komputer, Pengantar MPLS”,2003,pp 118.

[4]Stallings, William,"MPLS and IPsec" Protocol Journal. September 2001(2001):2-14.

[5]Editor Staff.”” Packet Magazine. First Quarter 2001:37-43.

[6]Cisco Sistem."Internet Connectivity Optios "White paper.
[7]URL:http://www.cisco.com/en/US/tech/tk436/tk 428/technologies_white_paper0 9186a00801281f1.shtml 08/29/2004.

[8]Rully Muttaqien, Bagus (NIM 23201167), "Simulasi Jaringan MultiProtocol Label Swithcing (MPLS)menggunakan Internet Protokol versi6(Ipv6)”,Surabaya: 2008

[9]Kunihiro Ishiguro, et al.(2006), "A routing software packages for TCP/IP networks Quagga 0.99.4”

[10]Joko Rubianto, Tri, "Studi Quality of Servis(QoS) untuk penerapan Multiprotocol Label Switching(MPLS)pada jarina IP”, Surbaya:2001 